\title{
FORENSIC INTERVIEWS OF CHILDREN: THE COMPONENTS OF SCIENTIFIC VALIDITY AND LEGAL ADMISSIBILITY
}

\author{
NANCY E. WALKER*
}

I

\section{INTRODUCTION}

The problems associated with assessments of children's reports of victimization in criminal proceedings came to national attention during the 1980s and 1990s in a series of highly publicized trials of daycare staff. ${ }^{1}$ In the McMartin Preschool case, ${ }^{2}$ more than 350 children claimed to have been molested at the preschool and a number of public locations including a market, a car wash, and a church. ${ }^{3}$ During interviewing, some children reported that, in addition to experiencing sexual abuse, they had been taken on plane rides and forced to drink blood and to watch animals being mutilated. ${ }^{4}$ Prosecutors said that the suggestive techniques used to elicit retrospective reports from such young children were appropriate, whereas the defense claimed that the interviewing and videotaping procedures were inept. ${ }^{5}$ When the trial ended in January of 1990, several jurors reported that they believed some of the children had in fact been molested but that the state had failed to prove the identity of the perpetrator(s). ${ }^{6}$

Copyright (C) 2002 by Nancy E. Walker

This article is also available at http://www.law.duke.edu/journals/65LCPWalker.

* Associate Director, Institute for Children, Youth, and Families, Michigan State University.

1. See, e.g., People v. Buckey, No. A750900 (Super. Ct., Los Angeles County, Cal. 1990) ("McMartin Preschool case"); State v. Fijnje, No. 89-43952 (Fla. Cir. Ct., 11th Judicial Cir., Dade County May 4, 1991) ("Old Cutler Presbyterian case"); State v. Fuster, No. 84-19728 (Fla. Cir. Ct., 11th Judicial Cir., Dade County 11th Cir. Oct. 9, 1985) ("Country Walk Babysitting Service case”); State v. Michaels, 625 A.2d 489 (N.J. Super. App. Div. 1993), aff'd, 642 A.2d 1372 (N.J. 1994) ("Wee Care Nursery School case"); State v. Kelly, No. 91-CRS-4250-4363 (Super. Crim. Ct., Pitt County, N.C. April 22, 1992) ("Little Rascals Day Care case"). Details of the allegations and findings in these cases are available in STEPHEN J. CECI \& MAGgIE BRUCK, JEOPARDY IN THE COURTROOM: A SCIENTIFIC ANALYSIS OF CHILDREN'S TESTIMONY 9-16 (1995).

2. Buckey, No. A750900.

3. Don J. DeBenedictis, McMartin Preschool's Lessons: Abuse Case Plagued by Botched Investigation, Too Many Counts, 76 A.B.A. J. 28 (1990); Bob Williams, Picking Up the Pieces; A Freed ExMcMartin Pre-School Teacher Still Haunted by Her Family's Shattered Life, L.A. TIMES, July 17, 1988, pt. 6 , at 1 .

4. David Shaw, Where Was Skepticism in Media?, L.A. TIMES, Jan. 19, 1990, at A1.

5. Sena Garven et al., More than Suggestion: The Effect of Interviewing Techniques from the McMartin Preschool Case, 83 J. APPLIED PSYCHOL. 347, 347 (1998).

6. McMartin Voices, EASY READER, Jan. 25, 1990, at 9. 
This three-year trial-the longest-running criminal trial in the history of the United States - cost taxpayers between thirteen and fifteen million dollars, produced no convictions, and destroyed the lives of many individuals connected to the case. ${ }^{7}$ In the end, it was not possible to determine whether the reports provided by the children interviewed were accurate.

Research completed since the McMartin trial shows that the skill of the interviewer directly influences whether a child relates a true memory, discusses a false belief, affirms details suggested by others, embellishes fantasies, or provides no information at all. ${ }^{8}$ For example, Sena Garven and colleagues demonstrated that the coercive techniques used by interviewers in the McMartin case elicited substantially more false allegations from children than did simple suggestive questions. ${ }^{9}$ This finding is particularly important given the fact that suggestive questions have long been known to have a negative impact on the quality of children's reports. ${ }^{10}$ When exposed to the "McMartin techniques" for less than five minutes, children in the study conducted by Garven and colleagues showed error rates of nearly sixty percent. ${ }^{11}$ Moreover, children subjected to social influence techniques became more acquiescent as the interview proceeded. ${ }^{12}$

As these findings demonstrate, the specific techniques employed by an interviewer have a direct effect on the quality of the report obtained, a conclusion that has been heeded in recent appellate court opinions. ${ }^{13}$ For example, in State v. Michaels, the New Jersey Supreme Court considered whether the state's interview techniques in the case had been "so coercive or suggestive that they had a capacity to distort substantially the children's recollections of actual events

7. See generally NANCY WALKer PERry \& LAWRENCE S. WRIGHTSMAN, THE ChILd WitNESS: LEGAL ISSUES AND DILEMMAS 5 (1991).

8. See, e.g., Garven et al., supra note 5; Nancy Walker Perry et al., When Lawyers Question Children: Is Justice Served?, 19 LAW \& HuM. BEHAV. 609 (1995); Nancy E. Walker \& Jennifer S. Hunt, Interviewing Child Victim-Witnesses: How You Ask Is What You Get, in EYEWITNESS MEMORY: Theoretical And ApPlied Perspectives 55 (Charles P. Thompson et al. eds., 1998); Amye R. Warren et al., "It Sounds Good in Theory, But ...": Do Investigative Interviewers Follow Guidelines Based on Memory Research?, 1 ChILD Maltreatment 231 (1996); Livia L. Gilstrap et al., Are All Leading Questions Created Equal?: The Effects of Various Types of Questions in Unstructured Interviews, Paper Presented Before the European Association of Psychology and Law and the American Psychology-Law Society, Dublin, Ireland (July 7, 1999) (on file with author).

9. Garven et al., supra note 5, at 348-50. These techniques included, for example, telling the child that the interviewer had already received information from another person regarding the topics of the interview, making positive and negative consequences contingent upon the child's responses, repeating questions already asked and answered by the child, and inviting speculation about past events. Id.

10. For reviews of the suggestive questioning literature, see DEBRA A. POOLE \& MiCHAEL LAMB, Investigative InTERVIEWs OF ChILdREN: A Guide FOR HElPing Professionals (1998); Stephen J. Ceci \& Maggie Bruck, Suggestibility of the Child Witness: A Historical Review and Synthesis, 113 PSYCHOL. BULL. 403 (1993).

11. Garven et al., supra note 8 , at 354 .

12. $I d$.

13. See, e.g., Idaho v. Wright, 497 U.S. 805, 812-13 (1990) ("The court found Dr. Jambura's interview technique inadequate because "the questions and answers were not recorded on videotape for preservation and perusal by the defense at or before trial; and, blatantly leading questions were used in the interrogation.”); Leyra v. Denno, 347 U.S. 556, 556 (1954); State v. Michaels, 625 A.2d 489 (N.J. Super. App. Div. 1993), aff'd, 642 A.2d 1372 (N.J. 1994). 
and thus compromise the reliability of the children's statements and testimony based on their recollections." ${ }^{14}$ An amicus brief signed by forty-five scientists provided the appellate court with a summary of research relevant to issues associated with the forensic interviewing of children and demonstrated the causative link between the use of highly suggestive interviewing techniques and children's flawed memories. ${ }^{15}$ The information presented in the brief contributed to the appellate court's decision to reverse the defendant's conviction. ${ }^{16}$

As the McMartin Preschool and Michaels cases illustrate, truth-finding involving assessments of children's retrospective reports may be seriously compromised, if not completely obscured, when interviewing techniques are faulty. What these cases teach is that it is necessary to establish and maintain standards for quality control in conducting and evaluating forensic interviews of children. Interviewers require information from both social science and the law, such as information on child development, memory, and communication as well as information on legal standards for assessing the admissibility of interview evidence. Interviewers also require state-of-the-art training in best practices in forensic interviewing. In addition, to maintain quality after initial training, interviewers should engage in frequent and sustained peer review, including systematic analysis of videotaped and transcribed interviews.

Part II of this article describes information that professionals need to know if they are to conduct valid interviews of children in forensic contexts. Part III describes evolving guidelines, protocols, and statutes regarding forensic interviewing of children. Part IV discusses some challenges associated with training interviewers in the use of forensic assessment techniques. Part V poses questions that could guide future research on forensic interviewing of children, particularly in the area of interviewer training.

II

\section{INTERVIEWERS' INFORMATION NEEDS}

\section{A. The Difference Between Therapeutic and Forensic Interviews}

The goals of a therapeutic session and of a forensic interview are, and should be, distinct:

The primary and sole role of the forensic investigator is to collect the facts of the case. In therapy, however, there is an emphasis on "helping," as opposed to getting the facts; therapists acknowledge that there are multiple depictions of their client's reality that need to be weighed before deciding which approach will be the most therapeutic. Depending on their theoretical orientation and perceived role, therapists may be interested in bringing to fruition intrapsychic conflicts that may or may not be realitybased. ${ }^{17}$

14. Michaels, 642 A.2d at 1377.

15. See Maggie Bruck \& Stephen J. Ceci, Brief on Behalf of Amicus Developmental, Social, and Psychological Researchers, Social Scientists, and Scholars, 1 PsYCHOL. PUB. POL'Y \& L. 1 (1995).

16. See Michaels, 642 A.2d at 1374.

17. CECI \& BRUCK, supra note 1 , at 290. 
Because this distinction in roles is an important one, several professional organizations have adopted guidelines explicitly stating that the forensic and clinical roles should be filled by two different individuals. ${ }^{18}$

\section{B. Legal Standards for Assessing the Admissibility of Interview Evidence}

An interviewer who completes an assessment using faulty or problematic techniques risks having the evidence thrown out of court-and appropriately so. No interview is perfect, of course, and interview evidence should not be ruled inadmissible simply because of a few harmless errors. Instead, courts should use standards for evaluating the probative value of forensic interviews. These standards will assist the court in ruling on the admissibility of the interview evidence and in determining the weight to be accorded that evidence.

As Federal Rule of Evidence 401 dictates, in a case that involves forensic assessment of a child's report, the assessment must be relevant to the issues at bar and material to the case. ${ }^{19}$ The assessment must also facilitate truth-finding without being either unfairly prejudicial or confusing to the jurors or judge. ${ }^{20}$ In addition, most jurisdictions impose special requirements for determining admissibility when an expert seeks to testify using techniques derived from social science research (such as forensic assessment of a child) in legal proceedings. The majority of states follow an approach taken from the Federal Rules of Evidence. In the federal courts, the literal requirements of the Rules were augmented during the 1990s by important decisions of the United States Supreme Court in Daubert v. Merrell Dow Pharmaceuticals ${ }^{21}$ and Kumho Tire Co. v. Carmichael, ${ }^{22}$ ultimately, the rule governing admissibility of expert testimony was amended accordingly. ${ }^{23}$ The commentary to the revision indicates that the

18. See, e.g., American Academy of Child and Adolescent Psychiatry, Guidelines for the Clinical Evaluation of Child and Adolescent Sexual Abuse, 27 J. AM. ACAD. CH. \& ADOL. PsYCHIATRY 655 (1988); American Psychological Association, Guidelines for Child Custody Evaluations in Divorce Proceedings, 49 AM. PSYCHOL. 677, 678 (1994); AMERICAN PROFESSIONAL SOCIETY ON THE ABUSE OF CHILDREN (APSAC), GUIDELINES FOR PSYCHOSOCIAL EVALUATION OF SUSPECTED SEXUAL ABUSE IN YOUNG CHILDREN (1990) (on file with APSAC).

19. FED. R. EVID. 401. According to Rule 401, “'relevant evidence' means evidence having any tendency to make the existence of any fact that is of consequence to the determination of the action more probable or less probable than it would be without the evidence." Id.

20. FED. R. EVID. 403. Rule 403 states, "Although relevant, evidence may be excluded if its probative value is substantially outweighed by the danger of unfair prejudice, confusion of the issues, or misleading the jury, or by considerations of undue delay, waste of time, or needless presentation of cumulative evidence." Id.

21. 509 U.S. 579 (1993). Under the Daubert standard, courts must ensure that the proposed expert testimony meets the basic test of relevance. In addition, they must determine whether experts' testimony reflects scientific knowledge, whether their findings are derived by the scientific method, and whether their work product amounts to good science. Id. at 591-94.

22. 526 U.S. 137 (1999).

23. Rule 702 was amended effective December 1, 2000, to read:

If scientific, technical, or other specialized knowledge will assist the trier of fact to understand the evidence or to determine a fact in issue, a witness qualified as an expert by knowledge, skill, experience, training, or education, may testify thereto in the form of an opinion or otherwise, if (1) the testimony is based upon sufficient facts or data, (2) the testimony is the prod- 
amendment, which added the three-factor analysis at the end of the rule, was designed to respond to Daubert and the many cases applying it, including $K u m h o$, in an effort to ensure the evidentiary reliability of such expert testimony through an assessment of its scientific validity. ${ }^{24}$ Presumably, states that base their evidence law on the federal model will adopt similar provisions. A number of other states impose a second set of criteria, known as the Frye $e^{25}$ test, to assess the admissibility of expert testimony based on scientific techniques. ${ }^{26}$ Depending upon the jurisdiction, criteria from any of these standards may be invoked in evaluating the probative value of a purportedly scientific technique. Interviewers, therefore, need to know which standard is applied by the courts in their jurisdiction.

1. The Requirements of Helpfulness and Relevance. The court has the discretion to admit expert testimony if it will assist the jury. ${ }^{27}$ The admissibility of an assessment of a child offered by an expert witness will be evaluated on the criteria of relevance, materiality, and probative value ${ }^{28}$ as well as on lack of unfair prejudice, confusion, or potential to mislead the factfinders. ${ }^{29}$ Two tests of relevance must be met: materiality and probative value. If the evidence is offered to prove a proposition that is not at issue, the evidence is immaterial and therefore will be excluded as irrelevant. ${ }^{30}$ For example, if evidence regarding retrospective assessment of a child's mental state has no bearing on the facts of a case, the evidence is immaterial and therefore will not be admitted. Even if the evidence directly addresses a fact of central concern to the substantive law (and therefore is material to the case), it will not be admitted unless the evidence "provides insight into the likelihood that the fact at issue exists." 31 This

uct of reliable principles and methods, and (3) the witness has applied the principles and methods reliably to the facts of the case.

FED. R. EVID. 702.

24. FED. R. EVID. 702 advisory committee's note.

25. See Frye v. United States, 293 F. 1013, 1014 (D.C. Cir. 1923). In Frye, the United States Court of Appeals for the D.C. Circuit ruled that the trial judge's exclusion of a purportedly scientific procedure was appropriate. Frye, the defendant in a murder case, had sought to demonstrate his innocence by introducing into evidence favorable results of a "systolic blood pressure deception test" he had taken. The Court of Appeals of the D.C. Circuit upheld the trial judge's exclusion of the blood pressure evidence on the grounds that it had not met the test of general acceptance. See id.

26. See, e.g., People v. Kelly, 549 P.2d 1240, 1245 (Cal. 1976) ("The primary advantage, however, of the Frye test lies in its essentially conservative nature. . Frye was deliberately intended to interpose a substantial obstacle to the unrestrained admission of evidence based upon new scientific principles."); Reed v. State, 391 A.2d 364, 368 (Md. 1978) ("[A]ccording to the Frye standard, if a new scientific technique's validity is in controversy in the relevant scientific community, or if it is generally regarded as an experimental technique, then expert testimony based upon its validity cannot be admitted into evidence."); People v. Wesley, 533 N.Y.S.2d 643, 644 (Albany County Ct. 1988) ("[I]t was necessary herein that a Frye hearing be held to determine the admissibility of this new kind of scientific evidence.").

27. See FED. R. EVID. 702.

28. See FED. R. EVID. 401.

29. See FED. R. EVID. 403.

30. See FED. R. EVID. 402 ("Evidence which is not relevant is not admissible").

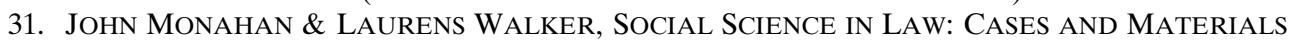
122 (4th ed. 1998). 
criterion is the test of probative value. In a case involving alleged sexual abuse of a child, for example, evidence regarding retrospective assessment of the child's mental state at the time of the alleged abuse may provide considerable insight into whether the alleged abuse in fact occurred. Did the child have some motivation for fabrication (such as revenge) or for recantation (for example, threats or promises of reward) or for truthfulness? Finally, even if both material and probative, relevant evidence may be excluded if its probative value is substantially compromised by the dangers of unfair prejudice, confusion of the issues, or misleading the jury. ${ }^{32}$

2. The Daubert/Kumho/Amended Federal Rules Standard. Under the standards set forth by the United States Supreme Court in Daubert, which were extended beyond scientific evidence to all expert evidence in Kumho, courts are required to ensure that the proposed expert testimony not only meets the basic test of relevance but also that it is reliable. ${ }^{33}$ In the case of scientific evidence, under Daubert, courts must determine whether expert testimony reflects "scientific knowledge," ${ }^{34}$ whether expert findings are "derived by the scientific method," ${ }^{35}$ and whether experts' work products amount to "good science." ${ }^{36}$ Although Daubert did not set out a definitive checklist or test of admissibility, the Supreme Court articulated four factors that would be helpful for judges to consider: (1) whether the technique can be (and has been) tested; (2) whether the theory or technique has been subjected to peer review and publication; (3) the known or potential error rate and the existence and maintenance of standards controlling the operation of a particular scientific technique; and (4) "general acceptance" within a relevant scientific community. ${ }^{37}$ Some methods for conducting forensic assessments of children generally meet all four factors; other methods meet only some, or even none, of the factors.

While the application of Daubert to social sciences has been somewhat problematic, the Court's extension of basic Daubert principles to all expertise in Kumho clearly signaled that courts must ensure the scientific soundness and integrity of methodology admitted as evidence. ${ }^{38}$ These generalized standards became effective in December 2000 when Federal Rule 702 was amended. Rule 702 now admits expert testimony only if "(1) the testimony is based upon suffi-

32. See FED. R. EVID. 403.

33. See Daubert v. Merrell Dow Pharms., 509 U.S. 579, 589 (1993) (noting that "under the Rules the trial judge must ensure that any and all scientific testimony or evidence admitted is not only relevant, but reliable").

34. Id. at 589-90 (stating that "[t]he subject of an expert's testimony must be 'scientific ... knowledge.' The adjective 'scientific' implies a grounding in the methods and procedures of science. Similarly, the word 'knowledge' connotes more than subjective belief or unsupported speculation.").

35. Id. (noting that "in order to qualify as 'scientific knowledge,' an inference or assertion must be derived by the scientific method").

36. Id. at 593 (commenting that "[t]his entails a preliminary assessment of whether the reasoning or methodology underlying the testimony is scientifically valid and of whether that reasoning or methodology properly can be applied to the facts in issue").

37. See id. at 593-94.

38. See Kumho, 526 U.S. at 147. 
cient facts or data, (2) the testimony is the product of reliable principles and methods, and (3) the witness has applied the principles and methods reliably to the facts of the case." "While not imposing an exclusive checklist, the commentary to the amendment, like Daubert, noted an additional set of factors that the court had found helpful in determining whether the expert testimony is "sufficiently reliable to be considered by the trier of fact." 40 These are:

(1) Whether experts are "proposing to testify about matters growing naturally and directly out of research they have conducted independent of the litigation, or whether they have developed their opinions expressly for purposes of testifying."

(2) Whether the expert has unjustifiably extrapolated from an accepted premise to an unfounded conclusion.

(3) Whether the expert has adequately accounted for obvious alternative explanations.

(4) Whether the expert "is being as careful as he would be in his regular professional work outside his paid litigation consulting."

(5) Whether the field of expertise claimed by the expert is known to reach reliable results for the type of opinion the expert would give.

Predicting precisely which forensic techniques are most likely to pass judicial scrutiny under the standards inspired by Daubert is a somewhat uncertain task, but reliance upon sound methodology and empirically verified results are clearly central features.

3. The Frye Standard. The Frye standard focuses on the concept of general acceptance. ${ }^{42}$ This standard is problematic, however, because to be admissible, any technique (including forensic assessment of children) needs to be (1) valid and reliable as well as generally accepted; (2) valid and reliable but not generally accepted; or (3) invalid and/or unreliable but generally accepted. The Frye test is met in either case (1) or (3), but it is met appropriately only in the first instance. Furthermore, the test fails to meet the court's objective in case (2). Because of these problems with the Frye test, courts have searched for other means for assessing the probative value of purportedly scientific methods. For this reason, the standards inspired by Daubert and codified in Rule 702 are preferable.

\footnotetext{
39. FED. R. EVID. 702.

40. FED. R. EVID. 702 advisory committee's note.

41. Id. (citations omitted).

42. See Frye v. United States, 293 F. 1013, 1014 (1923):

Just when a scientific principle or discovery crosses the line between the experimental and demonstrable stages is difficult to define. Somewhere in this twilight zone the evidential force of the principle must be recognized, and while courts will go a long way in admitting expert testimony deduced from a well-recognized scientific principle or discovery, the thing from which the deduction is made must be sufficiently established to have gained general acceptance in the particular field in which it belongs.
} $I d$. 


\section{Child Development}

One crucial task in conducting forensic assessments of children is to determine which factors, if any, impinge upon their ability to comprehend, recall accurately, and report past events. For example, did the child have some ulterior motive for falsification, withholding, or fabrication of information? At the time in question, did the child have the capacity to understand the events that transpired? Did the child, at that point in time, understand the difference between right and wrong? Whether we approach such questions from a psychological or a legal perspective, the essential question is this: How do internal mental states affect historical accuracy in remembering and reporting events? To answer this fundamental question, it is wise for professionals who conduct forensic assessments of children to be well-grounded in child development theory, as well as in the scientific literature on memory and suggestibility. ${ }^{43}$

1. Memory. The first steps in remembering an event are to perceive and pay attention to it. Interestingly, young children are no less aware of their surroundings than are older children and adults, and, generally speaking, alertness changes little after the first few months of life..$^{44}$ As they mature, however, children develop the ability to focus their attention in task-specific ways, so their capacity for reporting perception improves. ${ }^{45}$

In addition to perceiving and attending to an event, a child who is interviewed must have sufficient ability to remember the event. The child's memory of the event may be tested through different means, including recognition, ${ }^{46}$ reconstruction, ${ }^{47}$ and recall. ${ }^{48}$ Interviewers should be familiar with the advantages

43. It is outside the scope of this article to provide a comprehensive review of child development. Interested readers may consult other sources for more information on child development that has been written for attorneys. See, e.g., POOLE \& LAMB, supra note 10; WALKER PERRY \& WRIGHTSMAN, supra note 7; Nancy Walker Perry, Child and Adolescent Development: A Psychological Perspective, in CHILD WiTnESS LAW AND PRACTICE 459 (John E.B. Myers ed., 1987).

44. See Eleanor Gibson \& Nancy Radner, Attention: The Perceiver as Performer, in ATTENTION And Cognitive DeVElopment 1, 14-19 (Gordon A. Hale and Michael Lewis eds., 1979).

45. See POOLE \& LAMB, supra note 10 , at 35.

46. Recognition is the simplest form of remembering because it requires only that the child perceive an object as something that was perceived previously. Recognition is within the capacity of very young infants and even of animals. See generally BARbel InHELDER \& JEAn PIAGET, THE Growth OF LOGICAL THINKING FROM CHILDHOOD TO ADOLESCENCE (1958).

47. Reconstruction is a specialized method of retrieving material from memory that involves reproducing the form of information that was seen in the past. Reconstructing the scene of a crime is an example. Some forensic interview protocols, such as the "cognitive interview," recommend using a reconstruction technique called context reinstatement. See RONALD P. FISHER \& R. EDWARD GEISELMAN, MEMORY-ENHANCING TECHNIQUes FOR INVEsTIGATIVE INTERVIEWING: THE COGNITIVE INTERVIEW 95-102 (1992). In this technique, interviewees are encouraged to recreate the scene of an event mentally and to report everything they can remember by focusing on the surroundings, the smells and sounds, the temperature, the location of the furniture, or anything else about the event that may elicit memories they could not otherwise recall. See id.

48. Recall is the most complex form of memory test because it requires that previously observed events be retrieved from storage with few or no prompts. 
and pitfalls of each of these methods of memory retrieval. ${ }^{49}$ For example, recognition memory improves rapidly as children mature,${ }^{50}$ functioning particularly well during the elementary school years. ${ }^{51}$ It is tempting, therefore, to incorporate recognition tasks in interviews of children. One risk of this approach, however, is that it may foster suggestive interviewing, thereby leading to incorrect or tainted reports of memory. ${ }^{52}$ Use of reconstruction techniques generally leads to the recollection of more correct details than does a standard interview, although there may be some increase in confabulated details as well. ${ }^{53}$ Unlike these simpler forms of memory assessment, recall ability is strongly correlated to the subject's age..$^{54}$

Source monitoring, or the process of identifying the origin of one's knowledge of event memories, is another aspect of memory relevant to interviewers conducting forensic assessments. ${ }^{55}$ Source monitoring is involved, for example, when a person struggles to decide whether an event was personally experienced, experienced by a friend who reported it, viewed on television, or described in a book. ${ }^{56}$

Generally speaking, young children are more likely than their older counterparts to have difficulty in determining whether the information they "know" came from their own experiences or from other sources. ${ }^{57}$ Children are more likely to include information from the wrong source when interviewers ask closed questions that limit response options-such as "Did he ..."-rather than providing open-ended prompts-such as "Tell me what happened." 58 In addition, children who attribute information to the wrong source sometimes can re-

49. See, e.g., Nancy Walker Perry \& Larry L. Teply, Interviewing, Counseling, and In-Court Examination of Children: Practical Approaches for Attorneys, 18 CREIGHTON L. REV. 1369, 1387-88 (1984-85).

50. See, e.g., Nancy A. Myers \& Marion Perlmutter, Memory in the Years From Two to Five, in MEMORY DEVELOPMENT IN CHILDREN 191, 194-95, 198-204 (Peter A. Orenstein ed., 1978).

51. WALKER PERRY \& WRIGHTSMAN, supra note 7, at 109.

52. Id. at 118-19.

53. See generally Amina Memon et al., Eyewitness Performance in Cognitive and Structured Interviews, 5 MEMORY 639 (1997).

54. See, e.g., Barbara V. Marin et al., The Potential of Children as Eyewitnesses: A Comparison of Children and Adults on Eyewitness Tasks, 3 LAW \& HUM. BEHAV. 295 (1979). It is important to note, however, that although younger children may be able to recall less information, if they are interviewed nonsuggestively the details that they do report often have lower error rates than those of older children and adults. See id. at 304.

55. See POOLE \& LAMB, supra note 10, at 42-43.

56. See id.

57. One explanation for this problem is that young children have immature frontal lobe development. See, e.g., Daniel L. Schacter et al., True and False Memories in Children and Adults: A Cognitive Neuroscience Perspective, 1 PSYCHOL. PUB. POL'Y \& L. 411 (1995). As young children's brains develop, so too does their ability to monitor the sources of their knowledge-although even adults may have considerable difficulty with this task.

58. See Debra A. Poole \& D. Stephen Lindsay, Interviewing Preschoolers: Effects of Nonsuggestive Techniques, Parental Coaching, and Leading Questions on Reports of Nonexperienced Events, $60 \mathrm{~J}$. EXPERIMENTAL CHILD PSYCHOL. 129, 131-32, 136-39 (1995). 
construct what they actually experienced when interviewers explicitly ask them to do so, although this ability is limited at ages three and four. ${ }^{59}$ In addition:

For children, evidently, information obtained from parents and other sources is "real," and therefore references to "what really happened" do not always prompt the distinction between information obtained by personal experience and information that was only heard. It is difficult to rephrase such questions, however, because many young children have not yet mastered the distinctions among mental verbs such as remember, know, and guess. ${ }^{60}$

2. Language and Communication. Children who are interviewed in forensic contexts must also have the ability to report information about an experienced event. Research on the relationship between language comprehension and attention suggests that, regardless of age, children's performances in interviews may be more successful when they have a better understanding of the interview purpose and processes. ${ }^{61}$ Important differences between the autobiographical reports of preschool children and older children, however, also must be taken into consideration.

Younger children, for example, have more difficulty recognizing which event is being discussed during an interview. ${ }^{62}$ Even when children talk about target events at the outset, as the questioning continues they have a tendency to stray from the original topic. ${ }^{63}$

Topic drifts ... can have serious implications in forensic contexts, leading to bizarre interpretations of the child's experiences or even false accusations of other adults who happen to be mentioned. Topic drift might also lead adults to consider the child an unreliable witness. Interviewers therefore must be especially careful to ensure that children start, and stay, on topic. A simple strategy is to reword ambiguous prompts (e.g., "Can you tell me more?") into topic-focus prompts (e.g., "Can you tell me more about that time at the cottage?").

Another source of potential communication errors occurs when children are interviewed more than once about the same event or events. Because younger children are particularly likely to focus on different topics during the various interviews, their repeated accounts of the events appear to be less consistent than those provided by older children. ${ }^{65}$ Investigators who have reviewed the research in this area concluded that;

[c]ontent analyses of the children's narratives surprisingly revealed no decrease across sessions in either the total amount of information or the amount of descriptive information recalled, even after a [one]-year delay. The children reported different pieces

59. See POOLE \& LAMB, supra note 10 , at 44 .

60. Id. at 45 .

61. See id. at 37.

62. See, e.g., Poole \& Lindsay, supra note 58; Margaret S. Steward et al., Interviewing Young Children About Body Touch and Handling, 61 MONOGRAPHS SOC'Y FOR RES. CHILD DEV. 1, 119 (1996).

63. See Debra A. Poole \& D. Stephen Lindsay, Effects of Parental Suggestions, Interviewing Techniques, and Age on Young Children's Event Reports, Paper presented at the NATO Advanced Study Institute, RECOLLECTIONS OF TRAUMA: SCIENTIFIC RESEARCH AND ClinicAl PRACTICE (June 1996)(on file with author).

64. POOLE \& LAMB, supra note 10 , at 40 .

65. See id. 
of information across sessions, however, recalling less than [ten percent] of their information during each of two consecutive sessions. This pattern of session-to-session inconsistency is a well-documented pattern. ${ }^{66}$

Moreover, although information reported for the first time during a second interview is less accurate on average than information also reported during the first interview, information is not necessarily unreliable simply because it was not mentioned earlier. ${ }^{67}$

In addition, interviewers should be familiar with common errors in children's communications. ${ }^{68}$ Young children often engage in overextension, the extending of the meaning of a word to encompass actions or objects for which a child has no word. ${ }^{6}$ For example, young children might consider elbows and knees to be "private parts" because those body parts often are covered by clothing. Children also tend to underextend the meanings of words; in other words, they attribute to a word only part of the meaning the term has for adults. $^{70}$ For example, a child might deny that abuse occurred at "home" if the actions occurred in an apartment as opposed to a house.

Another potential source of error in communication with children is syntax, or the ordering of words to convey meaning. This problem is particularly apparent when adults use the passive voice as opposed to the active voice. ${ }^{71}$ For example, when a child hears, "You said your mom was hit by your dad," the child may visualize the scene as mom hitting dad, an error that may be avoided by using the active voice statement, "You said your dad hit your mom."

Finally, although children may use "big" words, oftentimes their understanding is more limited than their vocabularies. Researchers have found that sophisticated vocabulary - as well as complex syntax, use of negatives and double negatives, and multi-part and forced choice questions-reduces by nearly one-half the ability of interviewees to comprehend questions and to answer correctly, whether the respondents are children or adults. ${ }^{72}$ Therefore, it is especially important that interviewers use simple words and that they define and explain jargon.

66. Id. at 40-41.

67. See id. at 41 .

68. For a more complete description of typical errors, see WALKER PERRY \& WRIGHTSMAN, supra note 7 , at $126-27$.

69. See id. at 126.

70. See id. at 126-27.

71. See id. at 169.

72. See Walker Perry et al., supra note 8, at 622-25; Nancy E. Walker et al., Do Children Respond Accurately to Forced Choice Questions?: Yes or No, Paper presented at the NATO Advanced Study Institute: RECOLlECTIONS OF TRAUMA: SCIENTIFIC RESEARCH AND CliniCAL PRACTICE (June, 1996) [hereinafter Walker et al.] (on file with author); Warren et al., supra note 8, at 236-41. 
D. Common Problems in Interviewing Children

1. Distinguishing Truths, Lies, and False Beliefs. It is difficult to determine the point at which children understand the difference between a "lie" and a "truth," for these concepts are multifaceted: ${ }^{73}$

A truthful statement is characterized by five elements: (1) the statement is true; (2) the speaker believes the statement to be true; (3) in uttering the statement, the speaker intends the statement to be truthful; (4) the speaker wants to convey truthfulness; and (5) the speaker expects the listener to believe the statement because, of course, it is truthful.

Some research evidence suggests that young children's definitions of truthfulness may differ from those of older children and adults. For instance, four-yearold children may label any verbal indiscretion (such as swearing) a lie, ${ }^{75}$ and even most six year-olds do not consider the speaker's intention (such as "good" or "bad") when assessing whether an inaccurate statement is a mistake or a lie. . $^{76}$ Some time between the ages of six and ten, children begin to place more emphasis upon the belief system of the speaker than upon the factuality of the statement. $^{77}$ In other words, with increasing age, they begin to focus more on whether the speaker believes the statement to be true than on the objective truth of the utterance.

Generally speaking, the ability to distinguish between lies and truth varies as a function of two factors: (1) the form of the questions posed and (2) the topic of discussion. $^{78}$ In addition, there are three major limitations on incorporating truth/lie discussions into investigative interviews. ${ }^{79}$ First, children who "pass" so-called truth-lie tests are not necessarily more accurate or less suggestible than same-age peers who fail. ${ }^{80}$ Thus, truth-lie tests do not predict well which children will be accurate reporters. Second, there is no evidence that standard truth-lie tests encourage children to filter out inaccurate information. ${ }^{81}$ Third, young children's inaccuracies in reporting may be due more to errors in complying with the perceived demands of the interview situation and to errors in memory than to intentional deception. ${ }^{82}$ Current competency procedures, how-

73. For reviews of the development of truth-lie understandings, see, for example, STEPHEN J. CECI ET AL., COGNITIVE AND SOCIAL FACTORS IN EARLy DECEPTION 22-23 (1992); Nancy Walker Perry, Children's Comprehension of Truths, Lies, and False Beliefs, in TRUE AND FALSE ALLEGATIONS OF Child Sexual Abuse: Assessment And Case Management 73 (Tara Ney ed., 1995).

74. Walker Perry, supra note 73, at 75.

75. Jeffrey J. Haugaard, Children's Definitions of the Truth: A Replication and Extension, Paper presented at the biennial meeting of the American Psychology Law Society (Mar. 1992) (on file with author).

76. See generally Heniz Wimmer et al., Young Children's Conception of Lying: Lexical RealismMoral Subjectivism, 37 J. EXPERIMENTAL. CHILD PSYCHOL. 1 (1984).

77. See Abigail F. Strichartz \& Roger V. Burton, Lies and Truth: A Study of the Development of the Concept, 61 CHILD DEVELOPMENT 211, 215-18 (1990).

78. POOLE \&LAMB, supra note 10 , at 46.

79. Id. at 125 .

80. See id.

81. See id.

82. See id. at 47 . 
ever, do not address many of the reasons why children sometimes misreport events. ${ }^{83}$ Although revised procedures appear to be warranted, research on this topic is insufficient to make specific recommendations for practice.

2. Suggestibility. Suggestibility refers to the tendency to make errors elicited by exposure to (1) information that is false, (2) misleading questions or statements, and/or (3) social pressures that encourage particular types of answers. ${ }^{84}$ During the past quarter-century, the literature on interviewing children has been replete with discussions of the perils associated with suggestive questioning and of the interview techniques likely to induce suggestibility. ${ }^{85} \mathrm{Al}$ though a number of factors influence eyewitness reports, ${ }^{86}$ research studies that have manipulated these variables point to a number of general conclusions regarding children's suggestibility: $:^{87}$

(1) Younger children tend to be more vulnerable to suggestion than are older children. Preschoolers in particular have difficulty rejecting misleading information even after adults tell them that they were misinformed. $^{88}$

(2) Children are better able to resist suggestions about significant bodyrelated events than suggestions about other details or events. ${ }^{89}$

(3) Specific, misleading questions are very likely to produce erroneous responses. ${ }^{90}$

(4) Factors that generally impair memory (such as longer time lags before interviewing and questions about less salient events) also increase suggestibility. ${ }^{91}$

(5) Interviewers who have a bias about what might have happened tend to elicit more false information from children. ${ }^{92}$

(6) Nonsuggestive, open-ended interviewing cannot ensure that children will provide accurate reports, especially if those children have been exposed to misinformation in prior interviews or by other sources. ${ }^{93}$

83. See id. at 48 .

84. Id. at $48-49$.

85. For a review of this literature, see CECI \& BRUCK, JEOPARDY IN THE COURTROOM, supra note 1; Ceci \& Bruck, Suggestibility of the Child Witness, supra note 10; Amye R. Warren, Why Children's Suggestibility Remains a Serious Concern, 65 LAW \& CONTEMP. PROBS. 127 (2002).

86. The duration of time between the event and interview procedures, for example, may influence eyewitness reports. See Garven et al., supra note 8, at 355-57; POOLE \& LAMB, supra note 10, at 49-52.

87. See POOLE \& LAMB, supra note 10 , at 66.

88. Id.

89. Id.

90. Id.

91. Id. at 66-67.

92. Id. at 67.

93. Id. 
(7) In certain contexts, errors induced by misinformation procedures show disturbing stability over time and in repeated interviews, although such errors tend to drop out of children's reports at a faster rate than either spontaneous errors or accurate details. ${ }^{94}$

These conclusions support the argument that:

[I]t is not the case that children's event reports are generally distorted and unreliable, nor is it the case that children cannot be prompted to falsely report events that might be considered abusive. Rather, the quality of children's testimony is a joint product of their cognitive and social maturity, their experiences outside formal interviews, and the interviewing context.

3. Faulty Questioning Techniques. Other researchers have investigated different aspects of the impact of interviewer skill on children's reports. ${ }^{96}$ For example, Amye Warren and colleagues analyzed the questions posed in forty-two Child Protective Service interviews of children who alleged that they had been sexually abused..$^{97}$ Among other findings, they reported that interviewers only infrequently asked open-ended questions that invited narrative responses from children. ${ }^{98}$ When invitational utterances were used, however, they prompted longer and more detailed responses from the children. ${ }^{99}$

Nancy Walker and Jennifer Hunt conducted further analyses of Warren's forty-two Child Protective Service interviews, identifying several types of questions that compromised interview integrity. ${ }^{100}$ Faulty techniques included instances in which the interviewer modified the child's statement, ${ }^{101}$ used forcedchoice questions that limited the responses the child could give ${ }^{102}$ or used multipart questions. ${ }^{103}$ These faulty techniques increased the likelihood that children

94. See id.

95. Id. at 69.

96. See, e.g., Walker \& Hunt, supra note 8; Warren et al., supra note 8.

97. See Warren et al., supra note 8 , at 231.

98. Id. at 237 (noting that "[f]ewer than $10 \%$ of the interviewers' utterances were invitational, defined as encouraging an open-ended narrative response from children").

99. See id.

100. See Walker \& Hunt, supra note 8, at 74-79.

101. See id. at 74 (defining modification as "an instance in which an interviewer reworded a child's statement in a way that changed its meaning or claimed that the child made a statement that he or she had not made").

102. See id. at 77 (defining forced-choice questions as occurring "when interviewers phrase questions in a way that presents a limited number of response options," and noting that "[f]orced-choice questions can be considered leading because they suggest to children that there is a limited number of correct responses to a question, thereby inhibiting children's ability to provide their own answers"). Walker and Hunt provided the following example of a forced-choice question:

Interviewer: Did he do it real real hard or real real fast?

Id.

Child: $\quad$ Fast.

103. See id. at 78 (noting that multi-part questions occur when two or more inquiries with potentially different responses are contained within the same question). The following is an example of a multipart question: Was Sam wearing a green sweatshirt [no] or was Katie wearing a red sweatshirt [yes]? 
became inappropriately compliant, ${ }^{104}$ that the children chose one of the options offered by the interviewer whether or not it was correct, ${ }^{105}$ or that the children became confused. ${ }^{106}$

\section{E. Empirically-Based Best Practices in Forensic Interviewing of Children}

Although professional disagreements have been aired with respect to specific aspects of interviewing practice ${ }^{107}$ experts' recommendations for proper interviewing of children are remarkably consistent. ${ }^{108}$ The recommendations in this section are based upon empirical findings that have been subjected to peer review and publication and that appear to meet the test of "general acceptance" within the community of researchers of forensic interviewing techniques. These

104. Inappropriate compliance occurs when the child fails to correct the interviewer's false statement. Inappropriate compliance occurred, for example, when children failed to correct the interviewer's modifications. The authors provided the following example:

Interviewer: Do you know how old they are?

Child: (nods)

Interviewer: How old?

Child: $\quad$ Three months old.

Interviewer: Three years old ... okay ...

Child: [Child fails to correct interviewer].

Id. at 75-76 (emphasis added).

105. Walker and Hunt noted that "the children in our sample chose one of the answers suggested by the interviewer $65 \%$ of the time." Id. at 78 . In their study, which involved assessment of actual Child Protective Service interviews, the researchers could not know whether the forced-choice options provided by the interviewers were correct or incorrect. A follow-up laboratory study in which correctness of alternatives posed could be controlled found similar results. See Walker et al., supra note 72. Regardless of response correctness, students were more likely to choose the second forced-choice option than correct responses warranted, and less likely to choose the neither option that was appropriate. See $i d$. at 9 . Kindergartners produced significantly fewer correct responses to forced-choice questions than did older children (second or fifth graders). Children of all ages were more likely to correctly choose the first or second forced-choice option provided by the interviewer than to correctly provide the neither option. Kindergartners had a particularly difficult time providing that option. Children in all three age groups demonstrated a response set favoring selection of the second option provided by the interviewer. See id. at 13.

106. Children tended to become confused when they were confronted with multi-part questions, providing responses that did not appear to answer any of the questions posed in the multi-part query $61 \%$ of the time. See Walker \& Hunt, supra note 8, at 79.

107. See, e.g., WALKER PERRY \& WRIGHTSMAN, supra note 7, at 188-89 (discussing controversies regarding the use of anatomically detailed dolls); Ceci \& Bruck, supra note 10, at 430-34; Mark D. Everson \& Barbara Boat, Putting the Anatomical Doll Controversy in Perspective: An Examination of the Major Uses and Criticisms of the Dolls in Child Sexual Abuse Evaluations, 18 CHILD ABUSE \& NEGLECT 113; Garven et al., supra note 5, at 348-50 (noting difficulties with individual questioning techniques); Anne G. Walker \& Marcia J. McKinley-Pace, Questioning Children on Truth and Lies: A Real-World Look at the Problems, Paper presented at the Third National Colloquium of the American Professional Society on the Abuse of Children (June 1995) (discussing problems associated with assessment of truth-lie distinctions).

108. See generally British Home OfFICE, MEMORANDUM OF GOOD PRACTICE: ON VideO RECORDED INTERVIEWS WITH CHILD WITNESSES FOR CRIMINAL PROCEEDINGS (1992); Yael Orbach et al., Assessing the Value of Structured Protocols for Forensic Interviews of Alleged Child Abuse Victims, 24 CHILD ABUSE \& NeGleCt 733 (2000); PoOlE \& LAMB, supra note 10; Walker \& Hunt, supra note 8; Nancy E. Walker \& Matthew Nguyen, Interviewing the Child Witness: The Do's and the Don't's, the How's and the Why's, 29 CREIGHTON L. REV. 1587 (1996). 
recommendations for best practices, therefore, should satisfy judicial scrutiny under the Frye test, the Daubert standard, or the Federal Rules of Evidence.

1. Use Developmentally Appropriate Language. Interviewers need to understand that there are significant differences in language comprehension and usage between children and adults, ${ }^{109}$ a fact that has been recognized in some state statutes. ${ }^{110}$ Without that foundation, interviewers risk obtaining either contaminated information or poor-quality retrospective reports from children. The comprehensive guidelines for interviewing child witnesses in criminal proceedings developed by the United Kingdom's Home Office caution that "all interviews should be undertaken only by those with training, experience, and an aptitude for talking to children." 111

Despite this caution, a number of researchers have documented the deleterious effects of adults' use of confusing language when questioning children. ${ }^{112}$ For example, in a laboratory study of children's and adults' comprehension of various question forms, researchers found that even kindergarten-age children could correctly answer most (seventy percent) simply-phrased, straightforward questions regarding a recently viewed event, and that older children and adults correctly answered approximately ninety percent of the simply phrased questions. ${ }^{113}$ In contrast, children, adolescents, and young adults alike were confused by "lawyerese"- that is, convoluted question forms requesting the same information. ${ }^{114}$ Participants correctly answered fifty percent or fewer of those com-

109. See supra Part I.C.2.

110. See, e.g., CAL. EVID. CODE $§ 765(b)$ (1993):

With a witness under the age of 14 , the court shall take special care to ... insure that questions are stated in a form which is appropriate to the age of the witness. The court may in the interests of justice, on objection by a party, forbid the asking of a question which is in a form that is not reasonably likely to be understood by a person of the age of the witness.

See also R.I. GEN. LAWS §12-28-9(1) (2000) (noting the need "[t]o have explanations, in language understandable to a child of the victim's age, of all investigative and judicial proceedings in which the child will be involved"). WIS. STAT. $\$ \S 950.055(2), 950.055(2)(\mathrm{a}), 950.055(2)(\mathrm{b}), 967.04(7)(\mathrm{b})(1)$ (1995) provides:

Counties are encouraged to provide the following additional services on behalf of children who are involved in criminal or delinquency proceedings as victims or witnesses. . . Explanations, in language understood by the child, of all legal proceedings in which the child will be involved. ... Advice to the judge, when appropriate and as a friend of the court, regarding the child's ability to understand proceedings and questions ... the child's chronological age, level of development and capacity to comprehend the significance of the events and to verbalize about them.

111. BRITISH HOME OFFICE, supra note 108, at 3.

112. See, e.g., ANNE G. WALKER, HANDBOOK ON QUESTIONING ChILdREN: A LiNGUistiC PERSPECTIVE 6-7 (1994); Walker \& Hunt, supra note 8, at 61; Warren et al., supra note 8, at 234-35.

113. See Walker Perry et al., supra note 8, at 623. The researchers questioned kindergartners, fourth-graders, ninth-graders, and college students about a videotaped scenario. See id. at 625. Some questions were phrased in "lawyerese" (that is, including negatives, double negatives, multiple parts, difficult vocabulary, or complex syntax). See id. Other questions, matched for content with the "lawyerese" forms, were phrased simply. See id. Across age groups, participants correctly answered almost twice as many simply-phrased questions as "lawyerese" questions. See id.

114. The authors noted:

[S]tudents of all ages had considerable difficulty answering other forms of lawyerese questions. Specifically, students of all ages had difficulty correctly answering questions with multi- 
plex questions. ${ }^{115}$ Thus, adults risk miscarriage of justice when they interview children using complex language and question forms.

Based upon research findings, several specific strategies have been offered for increasing the likelihood that an interview of a child will be developmentally appropriate:

(1) Use active rather than passive voice;

(2) Avoid negatives and double negatives;

(3) Include only one query per question;

(4) Use simple words;

(5) Use simple phrases;

(6) Use the child's terms;

(7) Be alert to any signals that the child is having difficulty comprehending questions asked. ${ }^{116}$

2. Use a Research-Based Interview Protocol. Based on the results of empirical studies, a number of experts agree on the elements of a sound basic protocol for interviewing children. ${ }^{117}$ These elements include establishing rapport, explaining interview purpose, discussing interview "ground rules," emphasizing the use of open-ended questions, limiting the use of demonstrative aids (such as anatomically-detailed dolls), explaining legal proceedings, and formally closing the interview. Each of these elements, including descriptions of relevant research findings, is described below.

a. Establish rapport. The goal of the first phase of the interview is to establish rapport between the interviewer and the child so that the child can feel as relaxed and comfortable as possible in the interview situation. This phase serves as more than just an "ice-breaker," however. If correctly conducted, the rapport-building phase can "supplement the interviewer's knowledge about the child's social, emotional and cognitive development, and particularly about his or her communication skills and degree of understanding." 118 Moreover, when child abuse interviewers spend adequate time on rapport-building activities, the

ple parts having mutually exclusive answers (e.g., "At the end of the video was Sam mad [yes] or was Katie happy? [no]"). Indeed, correct answers to that question form never exceeded $35 \%$. On average, children and young adults produced correct responses to questions involving negatives, double negatives, or difficult vocabulary only $50 \%$ of the time at best.

Id. at 623,625 .

115. See id. at 625 .

116. See Walker \& Nguyen, supra note 108, at 1592-93.

117. See, e.g., British Home OfFice, supra note 108; Amina MEMon \& RAy Bull, Handbook OF THE PSYCHOLOGY OF INTERVIEWING (1999); POOLE AND LAMB, supra note 10; Nancy E. Walker, Retrospective Assessment of Children's Mental States, in PREDICTING THE PAST: THE RETROSPECTIVE AsSESSMENT OF MENTAL States IN CiVIL AND CRIMINAL Litigation 26-32 (Daniel W. Shuman \& Robert I. Simon eds., forthcoming 2002); Orbach et al., supra note 108; Walker \& Nguyen, supra note 108.

118. BRITISH HOME OFFICE, supra note 108, at 15-16. 
first substantive open-ended question regarding abuse tends to produce significantly more information than when inadequate time is spent on rapportbuilding. ${ }^{119}$

b. Explain the interview's purpose. The adult should tell the child why the interview is being conducted in language the child can understand. ${ }^{120}$ The interviewer should emphasize that the child is the one who has all the information, that the interviewer was not present at the event or events that took place in the past, and that he or she therefore cannot know what happened unless the child describes the event or events completely.

c. Discuss interview ground rules. Like adults, children have a right to know what will happen to them in various proceedings, including forensic interviews. ${ }^{121}$ They need to know which behaviors are permissible and which are prohibited. Two researchers who have conducted training internationally ${ }^{122}$ recommended the following guidelines for establishing interview "ground rules":

(1) Emphasize the importance of truth-telling, ${ }^{123}$

(2) Explicitly request detailed information, explaining that the interviewer cannot possibly know the correct details because the interviewer was not there at the time of the incident, ${ }^{124}$

(3) Teach the child how to appropriately use the "I don't know" response, ${ }^{125}$

119. See Kathleen J. Sternberg et al., Effects of Introductory Style on Children's Abilities to Describe Experiences of Sexual Abuse, 21 CHILD ABUSE \& NEGLECT 1133, 1140-41 (1997) (noting that good rapport-building, which includes the use of open-ended invitations to respond in a detailed fashion, results in more than twice as many details being provided by the child when the interviewer poses the first substantive question). Commenting on these findings (which came from their laboratory), Lamb and colleagues noted: "Children in the 'open-ended' condition continued to provide more information in response to subsequent invitations, suggesting that the initial training was successful in conveying the interviewers' desire for detailed description of the alleged events." Michael E. Lamb et al., Forensic Interviews of Children, in HANDBOOK OF THE PSYCHOLOGY OF INTERVIEWING 253, 268 (Amina Memon \& Ray Bull eds., 1999). 95.

120. See, e.g., POOLE AND LAMB, supra note 10, at 120; Walker \& Nguyen, supra note 108, at 1594-

121. See Convention on the Rights of the Child, G.A. Res. 44/25, U.N. GAOR, 44th Sess., Supp. No. 49, at 166, U.N. Doc A/44/736 (1989) [hereinafter CRC]. Adopted by the United Nations General Assembly in November 1989, the CRC is the most widely ratified treaty in the world. See generally NANCY E. WALKer ET AL., ChILDREN's Rights IN THE United STATES: In SEARCH OF A NATIONAL POLICY (1999). The CRC defines the minimum standards of human rights for children. Article 13 of the Convention guarantees children the right to see, receive, and impart information through any media. $I d$. at 31 .

122. Amina Memon (University of Aberdeen, Aberdeen, Scotland) and Nancy E. Walker (Michigan State University, East Lansing, Michigan, USA). See POOLE \& LAMB, supra note 10, at 126-30 for further detail on ground rules.

123. POOLE \& LAMB, supra note 10 , at $42-43$.

124.Id. at 169 .

125. See Karen J. Saywitz \& Lynn Snyder, Improving Children's Testimony with Preparation, in CHILD Victims, ChILD Witnesses: Understanding AND IMPROVING TESTIMONY 117 (Gail S. Goodman \& Bette L. Bottoms eds., 1993); Walker et al., supra note 72, at 13 (noting that kindergarten, second-grade, and fifth-grade children who had been trained to use the "I don't know" response gener- 
(4) Give the child permission to indicate when he or she does not understand a question; ${ }^{126}$

(5) Explain that asking a question more than once does not mean that the child answered the question incorrectly; the important point is for the child to understand the importance of answering each question truthfully each time it is asked, ${ }^{127}$

(6) Encourage the child to correct the adult if the interviewer incorrectly paraphrases a response or makes some other mistake, ${ }^{128}$

(7) Emphasize that the child is the one who will be doing most of the talking, not the interviewer. ${ }^{129}$

d. Substantive questions. Children's spontaneous, free-recall reports, although typically less detailed than those elicited by specific questioning, tend to be more accurate than reports obtained through direct questioning. ${ }^{130}$ Research suggests, however, that only a small fraction of interviewers typically asks openended questions when interviewing children. ${ }^{131}$ One explanation for this phenomenon is that children often are reluctant to provide free narrative accounts. An adult who creates a comfortable atmosphere for the interview, who takes time to establish rapport, and who exhibits patience and calm is more likely to elicit informative free-narrative accounts. ${ }^{132}$

It may be appropriate-and even necessary-to ask direct questions following the free-narrative portion of the interview, especially when questioning younger children. ${ }^{133}$ Here, the interviewer must balance competing interests in

ally used it appropriately and used it significantly more often than children who had not been so trained).

126. See Walker Perry et al., supra note 8, at 621 (noting that, although children do not always know when they do not comprehend something, even many kindergarten-age children can signal lack of comprehension if given the opportunity to do so in an interview).

127. See generally Debra A. Poole \& Lawrence T. White, Effects of Question Repetition on the Eyewitness Testimony of Children and Adults, 27 DEVELOPMENTAL PSYCHOL. 975 (1991); Debra A. Poole \& Lawrence T. White, Tell Me Again and Again: Stability and Change in the Repeated Testimonies of Children and Adults, in MEMORY AND TESTIMONY IN THE CHILD WiTNESS 24 (Maria S. Zaragoza et al. eds., 1995); Debra A. Poole \& Lawrence T. White, Two Years Later: Effects of Question Repetition and Retention Interval on the Eyewitness Testimony of Children and Adults, 29 DEVELOPMENTAL PSYCHOL. 844 (1993).

128. See generally Walker \& Hunt, supra note 8, at 77.

129. See POOLE \& LAMB, supra note 10, at 126-30.

130. See, e.g., Helen R. Dent, Experimental Studies of Interviewing Child Witnesses, in PRACTICAL AsPeCts OF MEMORY 236 (Michael M. Gruneberg et al. eds., 1991); Amye R. Warren \& Peggy Lane, Effects of Timing and Type of Questioning on Eyewitness Accuracy and Suggestibility, in MEMORY AND TESTIMONY IN THE CHILD WITNESS 44 (Maria S. Zaragoza et al. eds., 1995).

131. See, e.g., Walker \& Hunt, supra note 8, at 64 fig. 4.1 (depicting the finding that only two percent of their sample of forty-two Child Protective Service interviews included an open-ended question that served as an invitation to provide a free narrative).

132. See, e.g., Sternberg et al., supra note 119, at 1140-41.

133. See POOLE \& LAMB, supra note 10. Chapter 2, "Strengths and Weaknesses of Children as Witnesses: Implications for Developmentally Sensitive Interviewing," provides useful information on a number of issues related to interviewing children, including age-related issues. See id. at 33-72. 
resolving an apparent paradox: Young children in particular may need help recalling experiences, but use of direct questions and specific memory prompts may be especially likely to distort memory and increase suggestibility. ${ }^{134}$ Thus, many experts wisely urge interviewers to ask direct questions only if necessary, that is, if the free narrative does not provide sufficient information. ${ }^{135}$

e. Use of props/cues. Especially when talking with children, interviewers may be tempted to use props (such as anatomically detailed dolls or drawings) or other cues to aid memory and communication. There are two primary concerns with using props and cues in investigative interviews:

First, the presence of relevant cues might lead some children to elaborate from general knowledge or fantasy, thereby increasing the amount of inaccurate information they report. Second, the presence of irrelevant cues could be inherently suggestive, leading the investigators who selected the cues in the first place to confirm their a priori beliefs. ${ }^{136}$

After reviewing relevant research studies, two researchers drew four general conclusions regarding the use of cues and props in investigative interviews of children:

(1) Demonstrative aids (such as props and cues) often, but not always, help children report additional information;

(2) Some of the additional information elicited through the use of props and cues is erroneous;

(3) Real objects facilitate accurate recall more effectively than do toys;

(4) The use of cues magnifies age differences in the completeness of recall during the preschool years but decreases age differences during the school years. ${ }^{137}$

The benefits of using cues and/or props must, therefore, be weighed against the risk that their presence might result in more inaccuracies in children's reports. As several experts recommend, interviewers should use props and cues in therapeutic and forensic settings with great caution and typically only as a last resort. ${ }^{138}$ When such demonstrative aids are used, interviewers should use them only to encourage children to expand upon information that already has been discussed.

f. Closing the interview. Just as it is important to open the interview in a positive manner, it is equally essential to close the interview gracefully. ${ }^{139}$ Good closure has several advantages, including (1) providing an opportunity to thank the child; (2) allowing the interviewer to recap what the child discussed and to ask once again for verification of the veracity of the interviewer's summary; (3)

134. See id. at $60-61$.

135. See, e.g., id. at 137; Walker \& Nguyen, supra note 108, at 1598.

136. See POOLE \& LAMB, supra note 10, at 196.

137. Id. at $183-84,197-98$.

138. See, e.g., id. at 198-99; Walker \& Nguyen, supra note 108, at 1600. 
allowing the interviewer to explain what may happen next in legal proceedings; (4) giving the interviewer an opportunity to provide the child with a contact name and telephone number; (5) permitting the child to ask any remaining questions; and (6) offering a few moments to return to neutral topics. ${ }^{140}$

III

\section{GUIDELINES, PROTOCOLS, AND STATUTES REGARDING FORENSIC INTERVIEWING OF CHILDREN}

\section{A. Guidelines}

Because there is general consensus in the scientific community regarding procedures for conducting high-quality forensic interviews of children, both governmental and non-governmental organizations are beginning to publish and distribute recommended guidelines. The British Home Office has been a leader in this effort. ${ }^{141}$

1. Memorandum of Good Practice (United Kingdom). The Memorandum of Good Practice ${ }^{142}$ provides concrete recommendations for good practice in making videotapes of child interviews to be used in criminal proceedings in the United Kingdom. Although intended for this specific purpose, the Memorandum provides sound guidelines for interviewing children in a variety of other situations, both within the United Kingdom and in other countries. ${ }^{143}$

2. Guidelines of the American Professional Society on the Abuse of Children. The American Professional Society on the Abuse of Children ("APSAC") published guidelines for psychosocial evaluation in $1990 .{ }^{144}$ According to APSAC, these guidelines are intended to provide professionals who conduct investigative interviews with a framework for accomplishing their task. ${ }^{145}$ APSAC is in the process of publishing revised guidelines for investigative interviewing in child abuse cases. ${ }^{146}$

139. See Walker \& Nguyen, supra note 108, at 1599-1600.

140. See id.

141. See generally BRITISH HOME OFFICE, supra note 108.

142. Id.

143. See Rebecca Milne \& RAy Bull, InVestigative Interviewing: Psychology and PRACTICE (1999); POOLE \& LAMB, supra note 10, at 199-202 (describing procedures for interviewing children with special needs).

144. See APSAC, supra note 18.

145. APSAC states:

These Guidelines are intended to offer professionals charged with conducting investigative interviews a framework for performing this important task. The Guidelines reflect current knowledge and professional consensus about many of the issues related to investigative interviews. The Guidelines are not intended as a standard of practice to which investigators are expected to adhere in all cases. There is no single correct way to interview a child suspected of being a victim of abuse. Laws, court decisions, and local practice, as well as the specifics of the case, may dictate modifications. Investigators must remain flexible and continuously seek out new knowledge and research in applying these or any other guidelines.

APSAC, supra note 18 , at 1 .

146. A second edition of the guidelines was published in 1997. A third version is expected in 2002. 


\section{B. Protocols}

Other organizations have suggested using formalized protocols, rather than generalized guidelines, for conducting forensic interviews of children. Preliminary findings suggest that these extended scripts improve the quality and quantity of information obtained from forensic interviews. ${ }^{147}$ When using interview scripts, interviewers retrieve more information by asking open-ended questions, conduct better-organized interviews, and are more likely to follow focused questions with open-ended probes. ${ }^{148}$ One rationale for these findings is that interviewers have difficulty internalizing recommended interview techniques and therefore need more explicit directives than those typically provided by general guidelines or in training sessions or manuals. ${ }^{149}$

1. National Institute of Child Health and Human Development (NICHD) Investigative Protocol. The National Institute for Child Health and Human Development ("NICHD") recently published its protocol for investigative interviews of alleged sex-abuse victims. ${ }^{150}$ The NICHD protocol translates researchbased recommendations into a structured, but not inflexible, interview format. The protocol provides strategies for preparing children to be information providers, ${ }^{151}$ creating a supportive interview environment, ${ }^{152}$ adapting interview practices to children's developmental levels and capabilities, ${ }^{153}$ and maximizing interviewer reliance on questioning approaches that tap children's free recall memory. ${ }^{154}$

147. See Lamb et al., supra note 119 , at 268.

148. See id.

149. See id.

150. See Orbach et al., supra note 108 .

151. Strategies to achieve this goal include clarifying communication rules and training children to report event-specific episodic memories.

In the introductory phase, the interviewer introduces him/herself and his/her role, clarifies the child's task (the need to describe events in detail and to tell the truth), and explains the ground rules and expectations (i.e., that the child can and should say "I don't remember," "I don't know," "I don't understand," or correct the interviewer).

Orbach et al., supra note 108 , at 738 .

152. After the introductory phase, the interviewer may proceed with the rapport building phase:

The rapport[-]building phase which follows comprises two sections, both characterized by open-ended prompts. In the first, the interviewer attempts to create a relaxed, supportive environment and to establish rapport between the child and the interviewer. Children are encouraged to talk openly about both positive and negative issues and are prompted to describe experienced events in detail; such prompting 'trains' children to provide narrative responses to open-ended interviewer utterances and thus prepares them for the type of investigative prompts they will encounter later in the interview.

Id. (citation omitted).

153. In this regard, the protocol suggests, for example, minimizing linguistic complexity and avoiding interruptions. See id.

154. The NICHD protocol instructs interviewers how to maximize the use of open-ended questions and probes, introduce focused questions only after exhausting open-ended questioning modes, use option-posing questions only to obtain essential information at the end of the interview, and eliminate suggestive practices. $I d$. 
2. State of Michigan Forensic Interviewing Protocol. In 1998, the State of Michigan published its Forensic Interviewing Protocol. ${ }^{155}$ This protocol's purpose is "to obtain a statement from a child, in a developmentally-sensitive, unbiased and truthseeking manner, that will support accurate and fair decisionmaking in the criminal justice and child welfare systems." ${ }^{, 156}$

\section{Statutes}

Michigan has taken another innovative approach to forensic interviewing of children in the state by enacting legislation mandating the use of an investigative procedure, using as a model the forensic protocol developed by the Governor's Task Force. ${ }^{157}$ One likely outcome of this legislation is that interviewers may be questioned at trial regarding whether they were trained on and used the

Following the pre-substantive phase, the interviewer attempts to shift the child's focus to the substantive issues as non-suggestively as possible so that the recollection process can commence. Only if the child fails to identify the target event/s in response to the first completely open prompt ("Tell me why you came to talk to me today") does the interviewer employ progressively more focused prompts to identify the alleged abuse.

Once the allegation has been mentioned, the free recall phase begins with the first substantive invitation ("Tell me everything that happened from the beginning to the end as best you can remember"), followed by open-ended prompts ("Then what happened?" "Tell me more about that") aimed at eliciting spontaneous recall accounts of the alleged incident/s. As soon as the first narrative is completed, the interviewer determines whether the incident occurred "one time or more than one time" and proceeds to secure incident-specific information. Interviewers are instructed to communicate the need for accounts of specific incidents and to direct children to recount those events that are most accessible to memory. Open-ended questions and prompts are used exhaustively, with focused questions only used at the end of the questioning phase to elicit essential information that is still missing. The protocol recommends returning to an open-ended questioning mode following confirmatory responses to focused questions, a practice labeled as "pairing." In addition, contextual cueing (references to events, people, places or things mentioned by the child) and time segmentation (requests for information about blocks of time demarcated by events mentioned by the child) are used to refocus children on material they have disclosed before requesting elaboration using open-ended "invitations" (i.e., utterances requesting that the interviewees report everything they remember about something). Interviewers complete the questioning phase by asking children whether they have additional information to report before thanking them for their cooperation and shifting the discussion to a neutral topic for closure.

Id. at 738-39 (citations omitted).

155. See STATE OF MichigAn GOVERnOR's TASK FORCE ON CHILDREN'S JUSTICE AND FAMILY InDEPENDENCE AGENCY, Forensic INTERVIEWING PROTOCOL (1998) [hereinafter MichigAN PROTOCOL]. This publication (document FIA-PUB-779) can be obtained from the State of Michigan Family Independence Agency, 235 S. Grand Avenue, Lansing, MI, (517) 373-2035.

156. Id. at 1. A few years earlier, the Governor's Task Force on Children's Justice in Michigan had published A Model Child Abuse Protocol-Coordinated Investigative Team Approach. The 1998 Forensic Interviewing Protocol serves as an update to the earlier document. The features and approaches recommended in the Michigan protocol are very similar to those described for the NICHD protocol. This similarity is not coincidental, as the researchers who served as primary authors of each protocol (Michael Lamb at NICHD and Debra Poole at Central Michigan University) also collaborated on writing a text on forensic interviewing of children. See POOLE \& LAMB, supra note 10.

157. Telephone Interview with Zoe Lyons, Child Welfare Institute, Family Independence Agency, in Lansing, Mich. (Sept. 15, 2000) (noting that, under Section 8(6) of the Child Protection Law, "[e]ach county shall adopt an investigative procedure ... including using as a model the ... forensic protocol from the Governor's Task Force"). Technically, counties in Michigan may use another protocol if they so choose. See id. 
Forensic Interviewing Protocol. ${ }^{158}$ Whether this knowledge improves upon the best-practice standard in forensic interviewing remains to be tested.

IV

\section{TRAINING}

Although a great deal is known today about best practices in the conduct of forensic interviews of children, a challenge that continues to perplex researchers and practitioners alike is the question of how to train interviewers to consistently use empirically-based forensic techniques for obtaining the most complete and accurate reports possible. This problem has two components. First, we need to develop training approaches that are effective in eliminating poor interviewing techniques and in substituting good interviewing techniques, and second, we need to convince interviewers and their supervisors of the need for continuing education beyond initial training. Interviewers must appreciate that positive outcomes associated with even the most informative training programs decay over time without training "boosters" designed to maintain best practices. ${ }^{159}$ Moreover, interviewers need support from their superiors and from policy-makers who provide resources necessary to implement and sustain highquality forensic interviewing practices. Finally, interviewers need assurance that forensically sound interviews will withstand judicial scrutiny; in other words, they need assurance that, if they follow proper protocol, they, as interviewers, "displace" the defendant as being on trial.

\section{A. The Effects of Interviewer Training}

Approaches for training forensic interviewers have met with mixed results. Contrary to intuition, research on the value of training workshops generally has produced discouraging results. ${ }^{160}$ Initial findings suggested that workshops taught attendees to answer factual questions on tests, but that new knowledge rarely translated into improved practice. ${ }^{161}$

Researchers in one study, for example, evaluated the skills of social workers in Kentucky and California both before and after a ten-day, seven-module training course. ${ }^{162}$ Respondents evaluated the quality of the interviews using an

158. Interview with Debra A. Poole, Ph.D., Member, Governor's Task Force on Children's Justice [Mich.], in Haslett, Mich. (Feb. 18, 2001).

159. Telephone Interview with Barbara Sturgis, Ph.D., M.L.S., Center on Children, Families and the Law, University of Nebraska at Lincoln (Dec. 11, 2000).

160. See, e.g., Jan Aldridge \& Sandra Cameron, Interviewing Child Witnesses: Questioning Techniques and the Role of Training, 3 APPLIED DEV. SCI. 136 (1999); Amye R. Warren et al., Assessing the Effectiveness of a Training Program for Interviewing Child Witnesses, 3 APPLIED DEV. SCI. 128 (1999).

161. See Debra A. Poole, Forensic Interview Development and Training Project: PROgRam EVAluation For the SKillman Foundation GRANT to the STATE OF Michigan FAMILY INDEPENDENCE AGENCY (2000) [hereinafter POOLE].

162. K. M. Stevenson et al., Competency-based Evaluation of Interviewing Skills in Child Sexual Abuse Cases, 28 Social Work RES. \& ABSTRACTS 11 (1992). The course was developed by the American Association for Protecting, which is a division of the American Humane Association. Participants interviewed adult females who played the role of ten-year-old girls. 
instrument that tapped three conceptual areas: content-oriented questions, ${ }^{163}$ process skills, ${ }^{164}$ and behavioral skills. ${ }^{165}$ The average scores of the social workers in Kentucky were only slightly higher after training than before training, and the average scores in California were somewhat lower after training. ${ }^{166}$

These results suggest that information presented in lecture format fails to promote significant behavioral change, particularly when that information involves abstract or general principles. ${ }^{167}$ Recent studies confirm these problems. For example, one study found that a six-hour training course failed to improve several key interviewing skills, leading the authors to conclude that "workshop training programs may not adequately prepare [Child Protective Service] workers to conduct appropriate investigative interviews with children." ${ }^{168}$

Researchers in another study echoed these sentiments when they discovered that a ten-day program had no significant impact on interviewers' questioning styles. ${ }^{169}$ Similarly, a third set of researchers ${ }^{170}$ found no differences in perform-

163. Content-oriented questions included the interviewer's ability to state his or her name, determine the name and relationship of the alleged perpetrator, and clarify the child's terminology for private body parts. $I d$. at 428 .

164. Process skills included the ability to sequence questions logically and avoid leading questions. Id. at 429 .

165. Behavior skills included the ability to make appropriate eye contact and avoid touching the child. Id.

166. See id.

167. See Jan Aldridge, The Further Training of Professionals Dealing with Child Witnesses, in CHILDREN AS WiTNESSES 231 (Helen R. Dent \& Rhona Flin eds., 1992).

168. Kurt A. Freedman \& Tracy L. Morris, Investigative Interviewing with Children: Evaluation of the Effectiveness of a Training Program for Child Protective Service Workers, 23 CHILD ABUSE \& NEGLECT 701, 701 (1999).

169. See Warren et al., supra note 160. According to the authors,

[Twenty-seven] experienced interviewers attended a [ten]-day training institute designed to provide knowledge and skills for improving investigative interviews with young children. Participants completed pre- and post[-]training surveys assessing their knowledge of the scientific evidence regarding memory, suggestibility, and other aspects of children's ability to provide accurate accounts of events during interviews. They also conducted pre- and post[-]training interviews with preschool children about [two] previously experienced events. Participant's knowledge about children's abilities and the scientific basis of various interviewing protocols increased significantly after the training. However, training did not have a significant impact on interviewers' questioning styles or the amount of accurate information elicited from the children. Results indicate that successfully translating knowledge into practice requires multiple opportunities for skill practice and feedback.

Id. at 128 .

170. Aldridge \& Cameron, supra note 160. According to the researchers,

This study evaluated the effect of a [one]-week intensive training course on police and social worker forensic interviewing with children and investigated the actual types of questions employed by interviewers. Analysis of videoed interviews was used to compare trained and untrained interviewers on a series of rating scales designed to assess interviewer performance. The number of requests for free reports and the number of open, specific, leading, and nonleading questions used were obtained. The study found no differences in performance between trained and untrained interviewers on any rated behaviors with both trained and untrained interviewers rating poorly.... The results of this study suggest that the frequently adopted model of the short, intensive training course may not be the most effective way of training investigators to interview children, and more research is needed to establish the best way forward.

Id. at 136 . 
ance on any rated behaviors of untrained interviewers and individuals who had completed a one-week intensive training course on forensic interviewing. Both trained and untrained interviewers rated poorly. ${ }^{171}$ Such results have led to the conclusion that ongoing training, involving repeated practice and feedback, may be necessary to impart even basic interviewing skills. ${ }^{172}$

In contrast, trainers relying on structured interviewing protocols have had more success. For example, a pair of researchers ${ }^{173}$ developed one-and two-day forensic interviewing training workshops using a structured interview plus an interactive training model. Although the trainers earned high marks on evaluations of the course, they did not collect any data on changes in interviewer behavior after training. ${ }^{174}$

In contrast, Debra Poole formally evaluated the effectiveness of a two-day interactive training workshop model based upon Michigan's protocol for forensic interviewing of children. ${ }^{175}$ Poole conducted a program evaluation involving analyses of interview simulations from eleven volunteers (representing eleven different workshops), with each volunteer contributing an interview both before and after training. ${ }^{176}$ Unlike workshop evaluations from other states that failed to find significant behavioral changes even after as much as two weeks of training, Michigan's two-day workshops resulted in dramatic changes in interviewer behavior. ${ }^{177}$ After training, all tested attendees followed the phased format of the Michigan Forensic Interview Protocol. ${ }^{178}$ They improved their introductions, rapport building, topic introductions, and closings. ${ }^{179}$ In addition, they integrated legal competency and ground rule discussions into their interviews and used more open-ended prompts to elicit free narrative accounts from children. ${ }^{180}$ Table 1 provides the percentage of the eleven interviewers who engaged in proper forensic interviewing strategies before and after training.

171. See id.

172. See Federal Law Enforcement Training Center, VAlidation of A 9-WEek Basic LAW ENFORCEMENT FOR LAND MANAGEMENT AGENCIES (9-PT) REPORT (1992).

173. See Amina Memon \& Nancy E. Walker, Interviewing Children: Techniques for Improving the Accuracy and Completeness of Children's Reports, Training conducted at the Psychology and Law International Conference, Dublin, Ireland (July 6, 1999) (information on training materials on file with author).

174. A participant from Memon and Walker's 1999 session summarized the group's consensus that "the simulations were very useful and gave an opportunity to practice what we've learned." Unpublished evaluation (on file with author). The following year, the trainers offered a two-day interactive session for judges, attorneys, social workers, and school psychologists in Reykjavic, Iceland. Nancy E. Walker \& Amina Memon, Interviewing Children: Techniques for Improving the Accuracy and Completeness of Children's Reports, Training conducted at the University of Iceland, Reykjavik, Iceland (Apr. 11-12, 2000). Participants in the two-day session, which provided more time for role-playing, practice, and feedback, commented very positively on the hands-on approach to training. Unpublished results (on file with author).

175. See POOLE, supra note 161; MichigAn Protocol, supra note 155.

176. See POOLE, supra note 161 , at 1.

177. See id. at 11-12.

178. See id. at 11.

179. See id.

180. See id. 
TABLE 1

INTERVIEWER BEHAVIOR BEFORE AND AFTER TRAINING ON THE MICHIGAN FORENSIC INTERVIEWING PROTOCOL

\begin{tabular}{lcc}
\hline Interview Component & Pre-Training & Post-Training \\
\hline Provided introduction to interview process & $25 \%$ & $87 \%$ \\
Assessed child's legal competency & $9 \%$ & $91 \%$ \\
Discussed interview “ground rules" & $0 \%$ & $82 \%$ \\
Built rapport with person interviewed & $55 \%$ & $100 \%$ \\
Used a specific event as a rapport-building strategy & $0 \%$ & $36 \%$ \\
Introduced substantive topic in a neutral way & $18 \%$ & $73 \%$ \\
Used a neutral free narrative prompt & $45 \%$ & $100 \%$ \\
Provided proper interview closure & $0 \%$ & $82-91 \% *$ \\
\hline
\end{tabular}

Source: Debra A. Poole, Forensic Interview Development and Training Project: PROGRAM EVALUATION FOR THE SKILLMAN FOUNDATION GRANT TO THE STATE OF MiCHIGAN FAMILY INDEPENDENCE AGENCY (2000).

- depending upon closure component analyzed.

Poole offered several reasons for her training program's success. First, in contrast to other initiatives, Michigan's workshops trained on the basis of the state's formal protocol, an approach that was mandated by law. ${ }^{181}$ The availability of the formal protocol likely improved upon prior training attempts by providing more structure and specific interviewing tips. ${ }^{182}$ In addition, the twoday program included hands-on activities that engaged participants in the learning process, such as role-playing activities, and provided feedback and concrete suggestions throughout the workshop. ${ }^{183}$ Furthermore, the fact that interviewers in Michigan are required to follow the protocol likely provided motivation for behavioral change that may have been absent in other states. ${ }^{184}$ For example, Michigan interviewers may have been motivated by the desire to avoid cross-examination from defense attorneys at trial, who, pursuant to the statute's enactment, can ask interviewers whether they followed the state's protocol when they interviewed children. ${ }^{185}$ Because trained interviewers generally elicited better language samples from children, conducted competency checks, warned children about possible misunderstanding of questions, and used less suggestive prompts during initial portions of the interview, post-training interviews would leave defense counsel with fewer opportunities to challenge chil-

181. See WALKer PERry \& WrightSman, supra note 7.

182. See POOLE, supra note 161 , at 12 .

183. See id. at 11-12.

184. See id. at 3 .

185. See id. at 12 . 
dren's credibility. ${ }^{186}$ Poole's study, however, does not provide longitudinal data on interviewers' behavior at various points following training.

Michael Lamb and his colleagues also achieved promising results using a structured protocol format based upon a three-day seminar followed by monthly group and individual sessions. ${ }^{187}$ During the monthly individual sessions, trainers analyzed transcripts of participants' interviews and discussed them in detail. The progress of each investigator was monitored and displayed graphically. Feedback was provided to participants outside the individual and group meetings via letters, faxes, and telephone calls.

The researchers found that this intensive, hands-on approach to training yielded positive outcomes. ${ }^{188}$ The number and proportion of open-ended utterances were significantly higher in protocol interviews than in the non-protocol interviews in both the pre-substantive and the substantive phases of the interviews. ${ }^{189}$ In addition, protocol interviews contained significantly fewer directive, option-posing, and suggestive questions. ${ }^{190}$ Compared to interviewers not following the protocol, interviewers in the protocol condition also asked proportionally and absolutely more open-ended substantive questions before the first option-posing question was asked. ${ }^{191}$ The protocol interviews did not, however, elicit more substantive details on average than the non-protocol interviews, although children in the protocol condition provided proportionally more of the total number of details in their first narrative response than did children in the non-protocol condition. ${ }^{192}$

\section{B. The Need for Continuing Education and Training}

No consensus currently exists regarding the best approach or approaches for training forensic interviewers. While researchers need to focus attention on finding answers in this area, one conclusion is beginning to emerge: Without continued supervision, interviewers are likely to fall back on their old habits, that is, to regress into using familiar but less effective, or even counterproduc-

186. See POOLE, supra note 161.

187. See Lamb et al., supra note 119.

188. Id. at 268, noting:

Interviewers retrieve more information using open-ended questions, conduct better organized interviews, and are more likely to follow focused questions with open-ended probes (pairing), as we suggested. Interviewers clearly have difficulty internalizing recommended interview techniques and may need more explicit guidelines than those typically provided in training sessions or manuals, however intensive. In field settings, interviewers who follow scripted protocols seem to elicit more information from recall memory and to avoid more potentially dangerous interviewing practices than do interviewers who improvise, despite the apparent Id. disadvantages of inflexible standardized scripts.

189. Orbach et al., supra note 108 , at 741 .

190. Id.

191. Id.

192. Id. at $745-46$. 
tive, interviewing methods. ${ }^{193}$ After evaluating their intensive training program, Orbach and colleagues concluded:

We believe that the success reported here was achieved by dint of extended and intensive training, monitoring, and feedback. Whereas most training is brief and intensive, the training received by interviewers in the present study was both intensive and extended over several months. It involved repeated practice using feedback-monitored simulations and the systematic analysis of both simulated and (later) actual forensic interviews, all of which were recorded. In addition, research staff continued to provide detailed feedback even after the investigators began using the protocol in the field. Similarly intense, prolonged, and quality-controlled practice may be a necessary component of successful training. None of the studies documenting the ineffectiveness of training have involved such intense and prolonged practice and supervision. ${ }^{194}$

This research group also stated that:

[W] cannot overemphasize the value of continued peer review, training, role-playing, and the systematic analysis of videotaped and transcribed interviews. We believe that the frequent quality-control meetings between our research staff and the investigators played a crucial role in effecting and maintaining changes in the behavior of interviewers. ${ }^{195}$

\section{IV}

\section{CONCLUSIONS}

A great deal is known about high-quality forensic interviewing of children, including that:

(1) The purpose of a forensic interview is fundamentally different from that of a therapeutic interview;

(2) In a case that involves forensic assessment of a child's report, the assessment must be relevant to the issues at bar and material to the case;

(3) Different jurisdictions rely on different legal standards (for example, the Federal Rules of Evidence, the Frye standard, the Daubert standard) for evaluating the admissibility of evidence, so interviewers must be cognizant of the standards applicable in their jurisdiction;

193. See id. Similar views have been expressed by another researcher-trainer, Barbara Sturgis. Telephone Interview with Barbara Sturgis, Ph.D., M.L.S., Center for Children, Families and the Law, University of Nebraska at Lincoln (Feb. 6, 2001) (noting that pilot data from her laboratory supports the idea that continuous periodic review of videotaped interviews following initial training is required in order to maintain participants' skill in interviewing).

194. Orbach et al., supra note 108 , at 744.

195. Lamb et al., supra note 119, at 268-69. Empirical results to support this claim are provided in Dvora Horowitz et al., The Effect of Using a Scripted Interview Protocol and Training of Youth Investigators on the Quality of Interviewing Child Victims of Sexual Abuse [Hebrew], in EVALUATION OF INTERVENTION IN CORRECTIONAL SERVICES [Hebrew] (Y. Vozner et al. eds., 2000). Similar sentiments have been expressed by other researcher-trainers, including Amina Memon (University of Aberdeen, Scotland) and Nancy E. Walker (Michigan State University). See Memon \& Walker, supra note 173; Walker \& Memon, supra note 174; Interview with Debra A. Poole, Member, Governor's Task Force on Children's Justice [Mich.], in Haslett, Mich, (Feb. 15, 2001); Telephone Interview with Barbara Sturgis, Ph.D., M.L.S., Center for Children, Families and the Law, University of Nebraska at Lincoln (Feb. 6, 2001). 
(4) It is wise for professionals who conduct forensic assessments of children to be well-grounded in child development theory, as well as in the specific scientific literature on memory, language and communication, and suggestibility;

(5) Interviewers should be very familiar with empirically based best practices in forensic interviewing of children, including techniques for establishing rapport, explaining interview purpose and ground rules, eliciting the most complete and accurate reports possible, and closing the interview;

(6) Professionals who conduct forensic interviews of children should be familiar with respected professional guidelines and protocols that have withstood empirical scrutiny; and

(7) Professionals should receive specific training in forensic interviewing of children, preferably protocol-based, including supervised follow-up and peer review of videotaped and transcribed interviews.

Our work, however, is not yet complete. For example, we are only beginning to understand the most productive elements and approaches to training. Professionals still need to know definitive answers to the following questions:

(1) How much training is required to produce the desired results?

(2) Specifically, which elements of training produce the desired outcomes?

(3) How much follow-up is required to maintain the positive effects of training?

(4) How intense must that follow-up be in order to maintain positive effects over time?

(5) Does the use of structured protocols significantly improve general practice in the field (as opposed to in the laboratory)?

(6) Are the costs of intensive training worth the benefits achieved?

(7) Do statutes requiring use of structured protocols improve forensic interviewing and/or adherence to best practice in the real world? If so, how?

Answering these questions should contribute significantly to the creation of policies that promote best practice in forensic interviewing of children-scientifically valid practices that should pass muster under the standards inspired by Daubert and Kumho and recently incorporated into the Federal Rules of Evidence. 